\title{
A SCALE COMPARISON OF WAVES BREAKING ON A BEACH
}

\author{
M.J.F. STIVE \\ Delft Hydraulics Laboratory, P.O. Box 152, 8300 AD Emmeloord, The Netherlands
}

(Received April 25, 1984, revised and accepted December 4, 1984)

\begin{abstract}
Stive, M.J.F., 1985. A scale comparison of waves breaking on a beach. Coastal Eng., 9: $151-158$

A measurement programme, conducted in a small-scale wave flume, which comprised the breaking of periodic and random waves on a gently sloping beach, was partly repeated in a large-scale wave flume. The results are used here to make a scale comparison. The quantities considered in the comparison are wave heights, set-up and vertical profiles of maximum seaward, maximum shoreward and time-mean horizontal velocities. It appears that, both qualitatively and quantitatively, scale effects in these quantities are virtually absent in the wave height range of $0.1 \mathrm{~m}$ to $1.5 \mathrm{~m}$.
\end{abstract}

\section{INTRODUCTION}

In the research field of coastal engineering it seems to be generally accepted that small-scale breaking waves are qualitatively similar to large-scale breaking waves. Specific statements in support of this are made by Banner and Phillips (1974): "At larger scales of breaking, air entrainment may take place and the breaking wave is clearly visible as a whitecap, but (. . .) air entrainment is not a necessary concomitant to wave breaking", and by Peregrine and Svendsen (1978): "If the breaking front is of a height 1 to $2 \mathrm{~cm}$ then (. . .) there may be no air entrainment and yet there is a very turbulent flow with all the other qualitative characteristics of breaking". However, the existence of quantitative effects in the scaling of wave breaking has been suggested in several publications, see e.g. Führböter (1974) and Singamsetti and Wind (1980). Actual quantitative effects have been observed in the wave height ranges of a few centimeters (Diephuis, 1958).

An experimental verification of the qualitative and quantitative similarity between small- and large-scale waves breaking on a gently sloping beach has been made, based on a comparison of measurements of the wave height variation, the set-up and the internal velocity field. The latter concerns vertical profiles of maximum seaward, maximum shoreward and time-mean horizontal velocities. In a large-scale wave facility two experiments were con- 
ducted with initial conditions closely corresponding to those in small-scale experiments conducted earlier. In one of these experiments periodic waves were applied, in the other random waves were applied.

The following sections describe the experiments, discuss the results and present a conclusion.

\section{EXPERIMENTS}

Large-scale flume

The large-scale measurements were conducted in a recently completed, large wave flume. The main dimensions of the flume are a length of $233 \mathrm{~m}$, a width of $5 \mathrm{~m}$ and a depth of $7 \mathrm{~m}$. On account of a simultaneously running Dune Research Programme, the flume was filled with sand of a median grain diameter of $220 \mu \mathrm{m}$. The sandy beach was profiled into an initially plane, 1:40 slope.

Waves were generated by a piston-type wave board with water on one side only. The command signal of the wave board was primary harmonic only, so free second-harmonic wave components in the periodic waves were not suppressed.

\section{Small-scale flume}

The small-scale measurements were conducted in a wave flume of which the main dimensions are a length of $55 \mathrm{~m}$, a width of $1 \mathrm{~m}$ and a height of $1 \mathrm{~m}$. The concrete beach was plane and of a 1:40 slope.

Waves were generated by a piston-type wave board with a rotation adjustment, allowing for any wave board motion between pure translation and pure rotation. In the periodic wave experiments the free second-harmonic wave components were minimized by applying a combined primary and secondary harmonic command signal for the wave board.

\section{Large-scale instrumentation}

Surface elevations were measured by means of three methods. The standard method was performed with a gauge newly designed for use in the large flume, a so-called wave surface follower. The instrument consists of a vertical aluminium gauge with a conductivity sensor at the bottom tip. The gauge moves vertically by means of a servo system so as to maintain a constant immersion depth of the sensor. The vertical motion of the gauge yields the time variation of the surface elevation. Another method of measurement applied an acoustic meter, which detects sound reflections, sent vertically down over a distance of several metres. This method is less reliable due to disturbing secondary reflections. The third method, restricted to measurement of the regular wave height, consisted of simply measuring the wave 
crest and wave trough level by visual observation of a hand-carried measuring rod. The scale of these experiments is such that the accuracy obtained in the latter case (approximately $2.5 \mathrm{~cm}$ ) is sufficient. The three methods appeared to yield comparable results, so that no discrimination is made in their presentation.

Mean bottom pressures translated in mean water level variation (set-up) were measured by a piezometric system. Plastic tubes were fixed to the side walls with their open ends close to the bottom. The relatively narrow tubes ( $8 \mathrm{~mm}$ in diameter) were connected to stilling wells $(15 \mathrm{~cm}$ in diameter). This combination causes damping of the water level fluctuations. The levels were read by eye with an accuracy of $5 \mathrm{~mm}$.

In addition, measurements of the mean water level were made by averaging the signals of the wave surface follower and of the acoustic wave height meter. Response problems may be expected when measuring in sharply peaked waves. However, the agreement with the piezometric measurements appeared to be reasonable within the estimated accuracy, so that again no discrimination is made in presenting the results.

The horizontal velocity of the water motion and the instantaneous sediment concentration in the same location (used in a dune research programme) were measured by an Acoustic Sediment Transport Meter (ASTM). This instrument measures the water velocity and particle concentration using the principles of doppler frequency shift and intensity variation of backward reflected sound waves respectively. Accuracy of the velocity measurements is determined by the stability of a main electronic component, i.e. the frequency tracker. The inaccuracies thus introduced are estimated to amount to $\pm 2 \mathrm{~cm} / \mathrm{s}$. A description of the instrument is given by Jansen (1979).

\section{Small-scale instrumentation}

Surface elevations were measured by means of conductivity-type wave gauges. Although aeration influences the response of the gauges, the air content in the breaking waves was estimated low enough to cause only negligible deviations. Mean bottom pressures translated in mean water level variation were measured by a piezometric system consisting of taps $(3 \mathrm{~mm}$ in diameter) mounted flush with the bottom, connected by tubes to stilling wells. The water level in the wells was read by pointgauges with an accuracy of $0.1 \mathrm{~mm}$.

The velocity field was measured by a Laser Doppler Velocitymeter (LDV). This instrument measures the water particle velocity using the principle of doppler frequency shift of reflected laser light waves. The accuracy of the LDV is determined by the stability of a main electronic component, i.e. the frequency tracker. The inaccuracies thus introduced were found to amount to $\pm 1 \mathrm{~cm} / \mathrm{s}$. A description of the instrument is given by Godefroy (1978). 


\section{Large-scale measurements and procedures}

The large-scale experiments took place over three days. The periodic wave measurements were conducted on the first two days. On the first day the wave conditions were selected and surface elevations were measured. On the second day velocities and bottom pressures were measured. The random wave measurements were conducted on the third day, after reprofiling the beach into a nearly 1:40 plane slope again. The electric data signals were digitized by a minicomputer at $25 \mathrm{~Hz}$ and processed immediately after the data collection.

\section{Small-scale measurements and procedures}

The small-scale experiments were part of a more extensive measurement programme. In this programme surface elevation and mean bottom pressure measurements were in principle conducted prior to the internal velocity measurements. The latter took about 6 hours duration per wave condition while the first took about 3 hours per wave condition. The electric data signals were recorded on analog tapes. The tapes were digitized at $100 \mathrm{~Hz}$ for later processing.

\section{Periodic wave conditions}

The wave conditions of the regular, large-scale wave experiment correspond closely to those of a smaller scale test, viz. test 1 described in Stive and Wind (1982). The correspondence of wave conditions was not so much based on the deep-water wave steepness, but rather on a measure of the wave steepness at the breakpoint, viz. the ratio of breaking wave height, $H_{\mathrm{b}}$, over deep-water wave length, $L_{0}$. The reason for this was to avoid differences at the breakpoint (being the location of the initial boundary condition) caused by different friction effects up to the breaking point induced by the flume walls (concrete vs. glass) and bottom (concrete vs. sand). The conditions for the large-scale and the small-scale, regular wave test are indicated below.

\begin{tabular}{lll}
\hline & large scale & small scale \\
\hline bottom slope & initially plane $1: 40$ & plane $1: 40$ \\
& & \\
wave height horizontal section, $H_{\text {hor }}$ & $1.12 \mathrm{~m}$ & $0.15 \mathrm{~m}$ \\
still water depth hor. section, $D_{\text {hor }}$ & $4.19 \mathrm{~m}$ & $0.70 \mathrm{~m}$ \\
wave period, $T$ & $5.00 \mathrm{~s}$ & $1.79 \mathrm{~s}$ \\
wave height at breakpoint, $H_{\mathrm{b}}$ & $1.50 \mathrm{~m}$ & $0.18 \mathrm{~m}$ \\
breakpoint steepness, $H_{\mathrm{b}} / L_{\mathrm{o}}$ & 0.038 & 0.036 \\
deep water steepness, $H_{\mathrm{o}} / L_{\mathrm{o}}$ & 0.031 & 0.032 \\
\hline
\end{tabular}




\section{Random wave conditions}

The initial conditions of the random, large-scale wave experiment differ from the small-scale experiments performed earlier due to restrictions beyond the present scope. However, since the large-scale conditions are intermediate between the conditions of two earlier conducted small-scale experiments, a useful comparison may be attempted. The conditions of the random wave tests are as indicated below.

\begin{tabular}{llll}
\hline & large scale & & small scale \\
\hline bottom slope & nearly plane 1:40 & plane 1:40 & plane $1: 40$ \\
& & & \\
rms wave height horizontal section, $H_{\text {rms }}$ hor & $1.00 \mathrm{~m}$ & $0.14 \mathrm{~m}$ & $0.14 \mathrm{~m}$ \\
still water depth horizontal section, $D_{\text {hor }}$ & $4.19 \mathrm{~m}$ & $0.70 \mathrm{~m}$ & $0.70 \mathrm{~m}$ \\
wave peak period, $T$ & $5.41 \mathrm{~s}$ & $2.93 \mathrm{~s}$ & $1.58 \mathrm{~s}$ \\
deep water wave steepness $\left(H_{\mathrm{rms}} / L_{\mathrm{p}}\right)_{\mathrm{O}}$ & 0.023 & 0.010 & 0.038 \\
\hline
\end{tabular}

\section{PERIODIC WAVE RESULTS}

The small- and large-scale, periodic wave results are compared in Figs. 1 and 2. These results concern the wave height variation and the set-up as

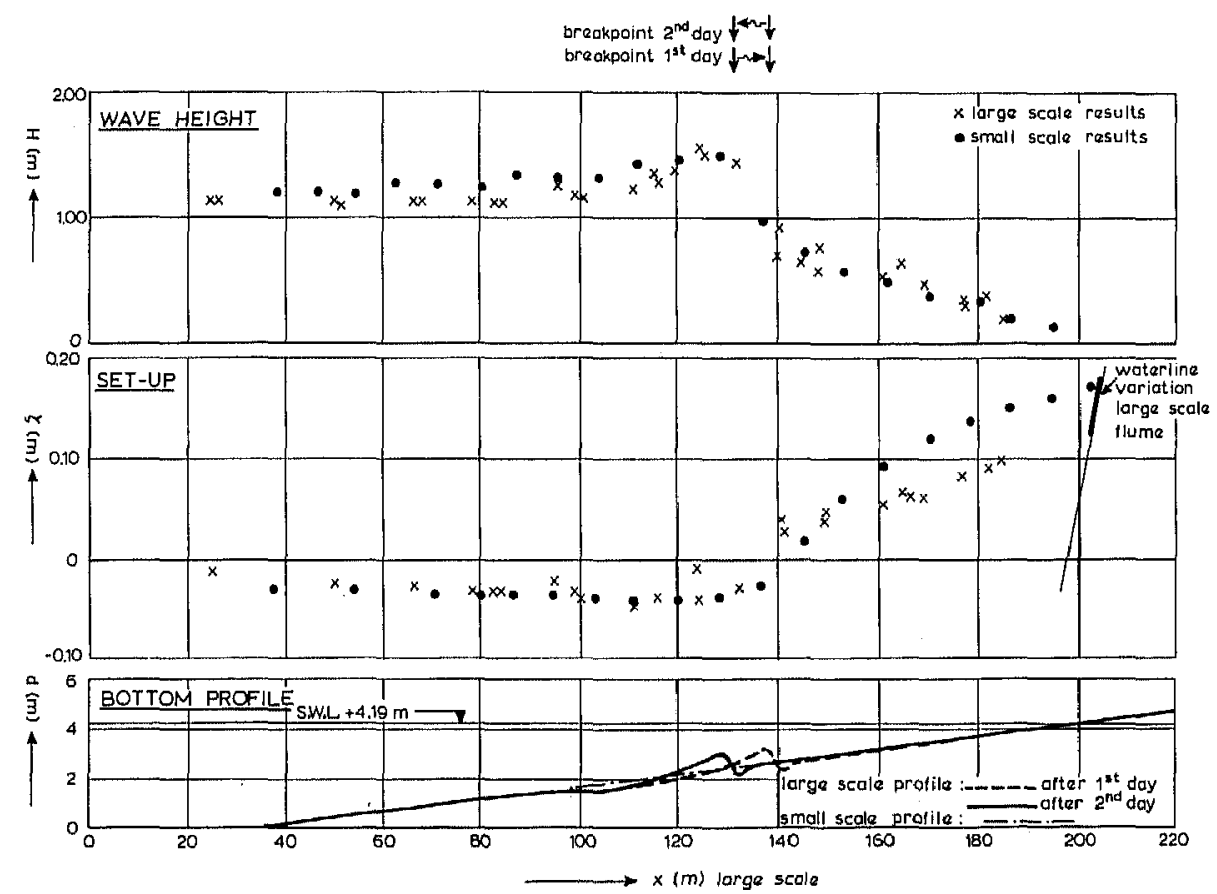

Fig. 1. Comparison between small- and large-scale measurements of wave height and setup in periodic waves. 

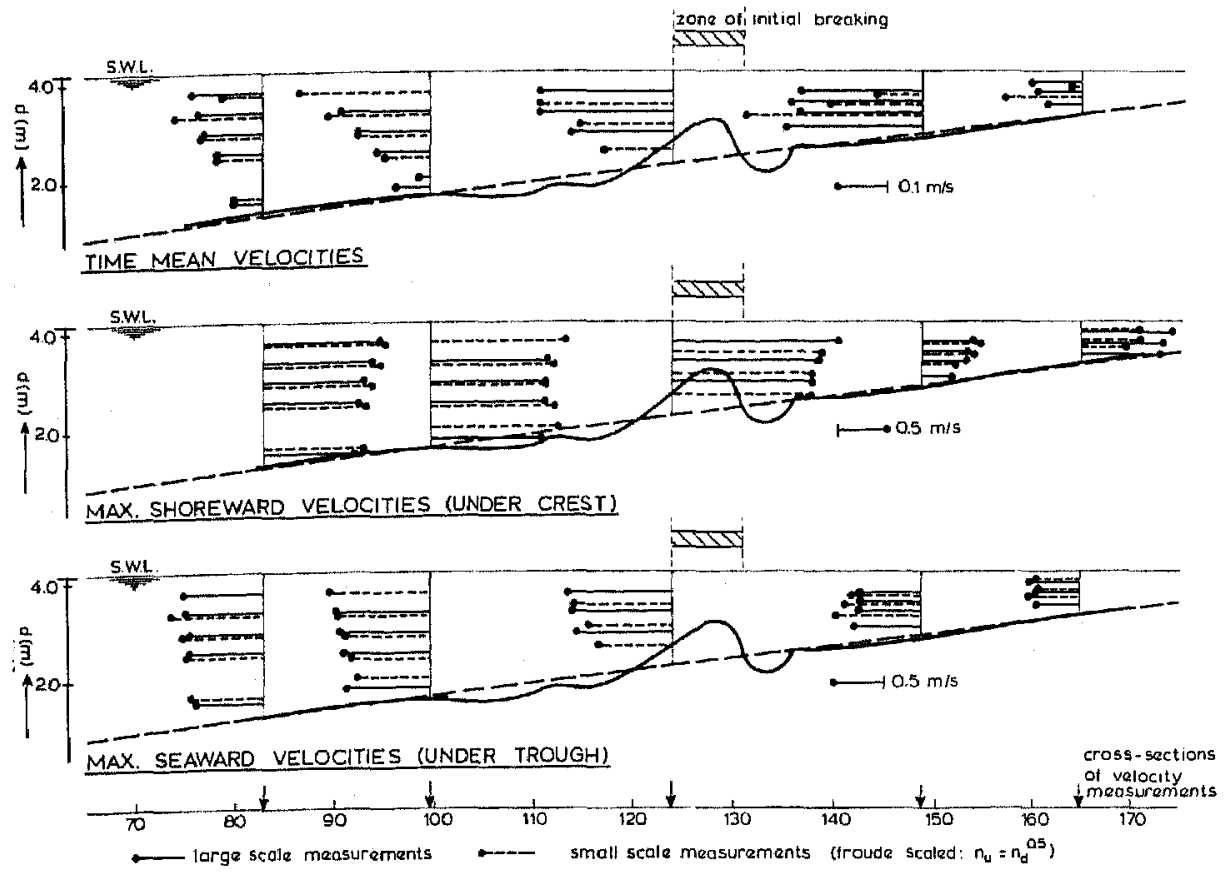

Fig. 2. Comparison between small- and large-scale measurements of time mean and extreme horizontal velocities in periodic waves.

external representations of the wave motion and characteristics of the velocity field as internal representations of the wave motion. The small-scale results are scaled up geometrically by the length-scale relation:

$n_{\text {depth }}=n_{\text {length }}=n_{\mathrm{H}_{\mathrm{b}}}=H_{\mathrm{b}_{\text {large scale }}} / H_{\mathrm{b}_{\text {small scale }}}=8.3$

and dynamically by the velocity scale relation according to Froude:

$n_{\text {velocity }}=n_{\text {depth }}^{1 / 2}$

The intersection of the still water level and the beach is taken as the reference point of position.

The small flume has a rigid bed. The large flume has a sandbed on which a breakpoint bar was formed. Yet, despite the formation of the bar, inspection of Figs. 1 and 2 reveals that the small- and large-scale results compare very well quantitatively. Good agreement is found with respect to the point of initial breaking, the maximal set-up and set-down, the decay of wave height, the time mean velocity field and the velocity field under wave crests and troughs. The qualitative variation of the set-up shows some discrepancy. At first glance the formation of the pronounced breakpoint bar may be expected to be a cause. However, absence of its effect in the other quantities makes a different cause likely, e.g. a difference in porosity of the beach (concrete vs sand). 

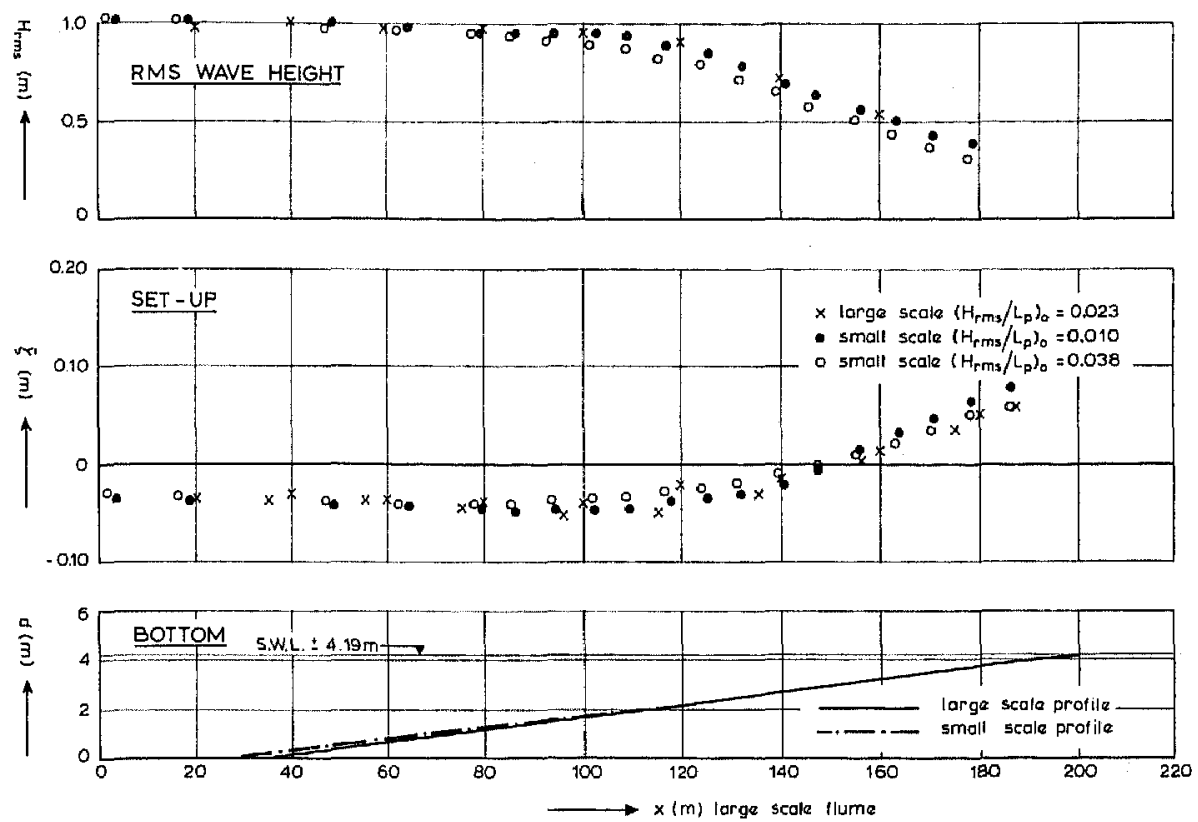

Fig. 3. Comparison between small- and large-scale measurements of wave height and setup in random waves.

\section{RANDOM WAVE RESULTS}

The small- and large-scale, random wave results are compared in Fig. 3. These results concern only the wave energy density variation and the set-up. The wave energy density is represented by $H_{\text {rms }}$ which is defined as $\left(8 m_{0}\right)^{1 / 2}$, where $m_{0}$ is the total energy density. The small-scale results are scaled up geometrically by the length scale relation:

$n_{\text {depth }}=n_{\text {length }}=\left(H_{\mathrm{rms}_{\mathrm{hox}}}\right)_{\text {large scale }} /\left(H_{\mathrm{rms}}^{*}\right)_{\mathrm{s} \mathrm{mall} \mathrm{scale}}=7.6$

where $H_{\mathrm{rms}}^{*}$ is $H_{\mathrm{rms}}$ at the location where the ratio $H_{\mathrm{rms}} / h$ in the small-scale cases equals $\left(H_{\mathrm{rms}} / h\right)_{\text {hor }}$ in the large-scale case. The intersection of the stillwater level and the beach is again taken as reference point of position.

Inspection of Fig. 3 reveals that the small-scale and large-scale bottom profiles differed slightly, particularly in the seaward half of the slope, seaward of the area of predominant wave breaking. It is believed that the results concerning the wave height decay and the set-up are not significantly affected by this. A comparison of the small-scale and large-scale results indicates good agreement. The influence of initial wave steepness is seen to be minor, so that the comparison is meaningful.

\section{SUMMARY AND CONCLUSION}

A scale comparison has been made of several characteristics of periodic and random waves breaking on a 1:40 beach. The quantities considered are 
wave heights, set-up and vertical profiles of maximum seaward, maximum shoreward and time-mean horizontal velocities. The measurements indicate that in these quantities there are no significant deviations from the Froude scaling, in a wave height range of approximately $0.1 \mathrm{~m}$ to $1.5 \mathrm{~m}$. This result implies that the "superficially" observed difference in air entrainment has no significant influence dynamically.

\section{ACKNOWLEDGEMENT}

This work was done as a part of the TOW Coastal Research Programme of the Ministry of Transport and Public Works (Rijkswaterstaat) of the Netherlands. The valuable comments of Prof. J.A. Battjes are gratefully acknowledged.

\section{REFERENCES}

Banner, M.L. and Phillips, O.M., 1974. On the incipient breaking of small scale waves. J. Fluid Mech., 65 (4): 647-656.

Diephuis, J.G.H.R., 1958. Scale effects involving the breaking of waves. Proc. 6 th Int. Conf. Coastal Eng., Ch. 11, pp. 194-201.

Führböter, A., 1970. Air entrainment and energy dissipation in breakers. Proc. 12th Int. Conf. Coastal Eng., Ch. 24, pp. 391-399.

Godefroy, H.W.M.E., 1978. Application of the laser doppler velocity measurement method in open and closed conduits. Proc. Flomeko, Groningen,

Jansen, R.H.J., 1979. An ultrasonic doppler scatterometer for measuring suspended sand transport. Proc. Ultrasonics International 79, Austria, pp. 366-371.

Peregrine, D.H. and Svendsen, I.A., 1978. Spilling breakers, bores and hydraulic jumps. Proc. 16th Int. Conf. Coastal Eng., Ch. 30, pp. 540-550.

Singamsetti, S.R. and Wind, H.G., 1980. Characteristics of shoaling and breaking periodic i waves normally incident to plane beaches of constant slope. Delft Hydraulics Laboratory, Report M 1371 .

Stive, M.J.F. and Wind, H.G., 1982. A study of radiation stress and set-up in the nearshore region. Coastal Eng., 6:1-26. 